\title{
SPORT SPONSORSHIP IN FINLAND: THE CASE STUDY OF FC JJK JYVÄSKYLÄ
}

\author{
Mihaly Szerovay \\ M.Sc. Doctoral Student \\ Department of Sport Sciences, University of Jyväskylä, Seminaarinkatu 15, 40014 Jyväskylä \\ $+358440155665$ \\ mihaly.szerovay@jyu.fi
}

\begin{abstract}
This paper seeks to analyse sport sponsorship in Finland via using the case study of Football Club JJK Jyväskylä from the Finnish Premier League. The results of a master's thesis conducted on FC JJK fans' sponsor awareness and sponsor orientation is presented. This research has provided implications to the management of the club, such as how to increase sponsorship efficiency, how to benefit from applying sponsorship alignment as well as relationship marketing. In order to successfully implement the study, an on-line survey, interviews, and participant observation was utilised. In addition, statistical data were obtained from the club. It has been concluded that JJK fans' sponsor awareness and attitude stood at a low level, therefore JJK's sponsorship strategy was advised to be reorganised. Conclusions from this paper might be beneficial for clubs from peripheral football countries, including those from Hungary as well. The size and level of Finnish and Hungarian football clubs are fairly similar and both countries can be considered as peripheral football countries at present.
\end{abstract}

Key words: sponsorship, football, fandom, Finland

\section{Introduction}

Sport in Finland is not as commercialised and professionalised as in other parts of Western Europe or in the US. It is rather characterised by the prevalence of the public and volunteer sector, which stems from historical, cultural and socio-economic reasons. Additionally, the number one sport is not football, as being the case in most European countries, but ice-hockey, of which highest division is the only fully professional league in Finnish sport.

Football Club JJK Jyväskylä has achieved considerable results at the Finnish level in recent years. They won the Second Division in 2006 and the following year the team acquired bronze medal in the First Division. After spending only two years there, JJK got promoted to the Finnish Premier League (Veikkausliiga), which is the number one football series in Finland, for the first time in their history. In 2011 the club came third and qualified for the UEFA Europa League. Growing interest of fans and sponsors has accompanied the outstanding results of the team, and it is reasonable to say that a football boom has been going on in the city. Apparently, the altered situation stemming from the improvements referred to above has given challenges to the management, primarily to those who are in charge of the marketing activities.

JJK Jyväskylä football team played in the semi-professional First Division category in Finland when the data collection of this study was carried out in 2008, which is actually the second highest level below the Veikkausliiga. This paper presents part of the results from my published master's thesis: 'Marketing Analysis of JJK Jyväskylä, A First Division Football Club in Finland'.

\section{The main points of the topic}

The topic of this paper is the examination and the analysis of the sponsorship activities of JJK Jyväskylä during the 2008 season. Due to the success previously mentioned, the business environment has changed considerably; growing number of game visitors, organisational changes, increasing interest in sponsorships, and more complicated operational procedures of the football club have been the most notable challenges to cope with. During the course of this research, JJK fans' sponsor awareness, sponsor orientation, and their relation to different levels of fan satisfaction and identification is carried out. The results of the study had been expected, firstly, to assist JJK to be able to fulfil the requirements of this new situation, and secondly, to add to the growing body of literature of sport marketing within the social sciences of sport. Few attempts (Clark 1992; Lipponen 1995; Itkonen, Ilmanen \& Matilainen 2009) have been made to conduct research in this area, and even less in the Finnish semi-professional environment.

When it comes to the research questions, they are formulated as follows: 
1. What characterises the sponsor awareness and sponsor orientation of JJK fans?

2. How JJK fan satisfaction and fan identification levels are related to their awareness of sponsors?

\section{Sponsorship in the Finnish environment}

Few attempts have been made to gather data on sponsorship in semi-professional football (Clark 1992), and even fewer in Finland. However, Lipponen (1995) tried to form a theoretical framework for sport sponsorships under Finnish conditions. According to his argument, putting emphasis on the necessity of the marketing concept of sport organisations is a relevant factor (Lipponen 1995). This statement seems reasonable given that it could serve, in general, as a base for the successful operation of a club or sport organisation. So far it has been lacking and a good example for this is the fact that no systematic process of measuring the outcome of sponsorships exists in Finland. According to research from the 1990s, 50 percent of the investigated teams somehow measure the success of sponsorship (Clark, 1992). A recent study (Itkonen et al. 2009) has found however, that "less than (sic) third of the companies evaluated whether the terms of the agreement were actually realized".

Furthermore, it should be noted that the Finnish football environment requires special attention when dealing with sponsorship deals. For instance, issues such as the geographic location of the city where the club belongs to, and the fact the in Finland football is considered the 'runner-up' spectator sport behind ice-hockey (Lipponen 1995), could act as examples. Another important phenomenon taken into account is the cooperation of volunteers and professional managers (Verhoeven et al 1999). Since the voluntary sector is fundamentally relevant in Finnish sport life, this issue cannot be avoided. JJK is an adequate example for this. There were only three full-time workers at the club in 2008 that had to work in collaboration with volunteers. The general manager, the marketing manager, and one more person who partly worked for JJK's management and partly managed the JJK youth academy, were these positions and in addition to that interns were employed from time to time. Besides, approximately 15-20 volunteers worked on match-days.

The role of the marketing concept has already been mentioned. Recording a database of the sponsors can be related to this topic, as well as the dilemma of sponsorship and philanthropy (Lipponen 1995). It is sensible to find out to what extent the companies enter into the business aiming at gaining financial profit and, on the other hand, just supporting the local team. Likewise, the investigation of the offer that the team can give to its sponsors is required. Naturally, the services that could be offered were limited in the case of JJK, since the games were not broadcast on national television; this fact makes the job of the marketers more challenging. Moreover, providing the opportunity of multi-partner cooperation, which can bring businesses together, is an excellent tool for networking, especially in the local level, since local sponsors are the relevant ones in semi-professional football (Clark 1992). Then again, the cultural characteristics of Finland should be taken in account. Furthermore, conducting market research on a regular basis is also of vital importance.

\section{Methodological Choices}

\section{Secondary Sources}

The use of existing statistics and resources were inevitable for the fruitful accomplishment of this research. First of all, it was necessary to obtain the results and rankings of the team from recent years. Although the final standings of certain championships are easily accessible via Internet, present research required detailed statistics that can be collected from the club or from the Football Association. Second, written sources about the history of the club and its role in the Central Finland territory, in sociological terms, were essential when coming to the issue of the evaluation of fan satisfaction and the approach towards sponsors. This data appeared to be invaluable because patterns in the behaviour of fans or sponsors can be understood only if one has background knowledge about the relationship between the local communities and the club.

\section{Survey}

The appropriate method that helps to gather empirical data about the opinion, beliefs and attitudes of the fans is the questionnaire. "Surveys can use a random sampling technique to recruit participants, relatively small sample sizes can be used to generate findings." (Mathers, Fox, Hunn 2006, p.7) Since this was the most relevant resource that helped to implement this study successfully, the creation of the questionnaire required special care. However, its drawbacks must be taken into account as well: "Surveys can tell us how many people behave in a certain way . . but they may be limited in the information they can provide as to why this is so." (Mathers, Fox, Hunn 2006, p.7)" The data collection was likely to be the easiest when JJK played at their home facilities and numerous crowds come together. With the help of some volunteers many responses could have been obtained and thus the rate of responses would have been higher than those sent via email. However, as a complementary option, questionnaires posted by email such as ones available at the website of the club seemed also as reasonable solutions. Nevertheless, sampling must be carried out in a way that both 'average' fans and fans who are sponsors at the same time will be asked as well. Eventually, a decision was made to use an online survey, which was available from the website of both JJK and the local newspaper, in its Finnish name Keskisuomalainen , in October 2008.

Questions aimed at obtaining information about fan satisfaction and fan identification, fans' intention to attend future games, as well as their attitude towards sponsors. Obviously, the questions were put in a way that all respondents would easily be able to answer them given that the language of the questionnaire is English. 


\section{Interviews}

Interviews with the club officials were essential to receive general information about the operation of the club, particularly about marketing activities. There were only three full-time workers employed by JJK football club when the data collection was carried out and even if they have their own scope of activities, it was at times problematic to separate the nature of their tasks. As previously mentioned, managing director, marketing manager, and a third person who partly worked for JJK's management and partly managed the JJK youth academy, were these positions. It seemed reasonable to ask the participation of the employees that filled in the first two positions specified above. The use of semi-structured interviews appeared to be applicable in all cases since the topic to focus on was fairly clear.

\section{Ethnography}

Due to the fact that the writer of this paper was the player of the researched club, it is felt relevant to highlight the influence of this factor on this study. Nearly every aspect of the research, such as planning, data collection via interviews and questionnaires, discussion and conclusion, were affected as well as facilitated by that fact mentioned. According to Atkinson (2007): "Ethnographic (or field) research provides a detailed description of a different culture, or sub-culture, from the view of an insider, allowing a greater understanding of that culture through its core method, observation." In this case the culture mentioned refers to JJK and its environment. This explanation implies that the researcher being an insider could have better opportunity to interpret the collected data on the club and its fans, due to understanding the relevance of the knowledge available and produced, and how this can be presented as subject matter. Observation was carried out on a daily basis, during football practices, meetings and interviews with the leaders of the club and naturally, during games.

\section{Measures}

The survey utilised in this study was planned thoroughly in order to get appropriate data and be able to achieve the goals set beforehand. Accordingly, it was divided in various sections based on the necessities of the information that needed to be acquired. The different divisions were formed as follows: First, some basic questions obtained socio-demographic data from the respondents, including age, gender, highest education, place of residence, and nationality. In addition to these, the number of games seen in the 2008 season, the status related to JJK (fan, sponsor or both), the way of attending games (alone, friends, family) and the possible possession of a season ticket were set to find out the information indicated above.

\section{Fan satisfaction related to sponsor awareness}

This section was created with an attempt to find out the sponsor awareness of JJK fans by applying the following question: 'Do you remember any of the sponsors from the announcer/stadium/player's kit?' Apart from this, information of fans' attitude towards merchandising products was to be ascertained: 'Do you know if it is possible to buy JJK products in Jyvaskyla?'; 'Do you have any products related to JJK?" and finally; 'Would you buy more if there was a wider range on offer?'

\section{Sponsor orientation}

Obtaining data from fans' sponsor orientation was accomplished by adapting a table from Shaw \& McDonald (2006), which were constructed to conduct a research on season-ticket holder satisfaction and sponsor-related behaviour. Respondents were asked to express agreement or disagreement with the following statements: 'I pay little attention to sponsors'; 'I know little about sponsors but I would like to know/have more information about sponsors' products'; 'If I think all the brands are the same, I try to use the sponsor's product.' These first three elements were based on Shaw's \& McDonald's work, whereas the coming two were added, taking into consideration the specificities of the present study, such as JJK players' jersey full of advertisements that presumably baffle spectators, and commercial messages by means of loudspeakers: First, 'The high number of sponsors in the stadium and on the players' kit confuses me.' and second, 'The announcements via loudspeakers during the game are efficient.'

\section{Data Collection}

Along the first part of this research, data was collected from secondary sources, such as websites of Football Club JJK, the Finnish First Division and the Finnish Premier League. Furthermore, data was also obtained from the archives of JJK and from interviews conducted with JJK's general manager, Joni Vesalainen, and via informal conversations with Ilkka Hyppönen, marketing manager. Three semi-structured interviews, two in 2008 and one in 2009 were carried out with Joni Vesalainen. Again, it is believed essential to mention that the researcher was a member of the investigated organisation, which enabled meetings, interviews, observations and so on, which would not have been possible or would have been more limited for a non-member.

Subsequently, a sport fan questionnaire was developed and a convenience sampling technique was employed, which "utilises readily available subjects and sampling often used in small scale localised research projects". (Hancock 2002, p 15)

To achieve potential respondents, a combination of activities was used. First, during one of JJK's home games, flyers with information on the on-line questionnaire were distributed and this was also reinforced via loudspeakers before the game and at half-time. Second, articles were featured on the website of JJK and that of KSML local newspaper. KSML is the most relevant daily paper of Central 
Finland and a separate section is dedicated to the football club on its website with news, videos and player profiles etcetera. The articles informed about present research that JJK's goalkeeper is conducting and asked the readers/fans to visit the address presented there and fill out that on-line questionnaire.

The 'power of word-of-mouth' was also utilised in order to get more respondents. Taking into account the environment of this study, which is a small town that likes sport and the researcher being a student of the sport faculty of the local university, word-of-mouth has proved to be an efficient way of spreading information for the on-going study. Furthermore, the fact that the researcher was a player of the club simplified all procedures given he could benefit from being in touch with many people in Jyväskylä.

In a few days 208 responses were obtained, out of which 188 were valid. However, the representativeness of the sample is complicated to assure for various reasons. Determining the population of JJK fans seems to be an immense task given that it is not known exactly how many JJK fans there are and in addition, the term fan must be clarified first. The difference between spectators and fans are as follows:

Whereas a spectator of sport will observe a spectacle and forget it quickly, the fan continues his interest until the intensity of feeling toward the team becomes so great that parts of every day are devoted to either his team or in some instances, to the broad realm of sport itself. (Pooley 1978, p. 14)

In the context of this paper, the term 'fan' is used according to the interpretation above. Without knowing the exact population of JJK fans, carrying out the sampling and issues of reliability and validity also become problematic. This should be taken in account when talking about the limitations of this study. However, since JJK did not possess a database on the fans in 2008 , the best possible way was followed to realise this investigation, which is the previously mentioned convenience sampling technique.

Concerning the question of validity, present work cannot assure all four steps of validity (Research Methods Knowledge Base 2010). After examining each validity type, it can be concluded that the first three steps are likely to be confirmed: there is a relationship between cause and effect; the relationships are casual; and the operationalisation of the ideas of cause and effect were successful, which proves the existence of conclusion validity, internal validity, and construct validity. However, external validity should be handled with care, because generalising of the proven effects might not be possible to carry out due to the method of sampling. In addition, the nature of this research, namely a case study investigating a football club that is in the process of development, requires that the generalisation of the results should be questioned.

The analysis of the acquired data was completed with the help of SPSS statistical program, with the utilisation of the following statistical methods: frequencies, descriptives, crosstabs, tables of frequencies, means, one-way ANOVA and correlations.

\section{Results and discussion}

\section{Sponsor orientation and awareness}

JJK had around 200 sponsors in 2008. (J. Vesalainen, personal communication, July, 17, 2009). This research has shown that only 13 of them were remembered at least 10 times by the 188 respondents who filled out the on-line questionnaire that measured fans' sponsor orientation and awareness. Among the 10 most recalled sponsors, merely 3 reached considerable results. Firstly, Harvia, a famous Finnish sauna producer, which was called up by around $40 \%$ of the respondents and has been one of the main sponsors of JJK, allocated several spots in the stadium and on the most visible place of the players' shirt. Secondly, around 23\% of the respondents remembered Peugeot, whose logo has also been situated in the front of players' shirt. Moreover, some cars, which were easy to recognise in the city of Jyväskylä, given that huge JJK logos and other promotional material were painted on them, were provided to the club by the company. Lastly, Osuuspankki, a Finnish bank, had a recall rate of $20 \%$. Due to the reasons explained above, it is no wonder that these brands were called up in higher numbers than others. In addition to this outcome, one-third of the respondents did not name any sponsors, either because they did not remember any or due to being incurious towards the sponsorship issue.

Subsequently, another significant finding to emerge from this study is that more than half of the supporters are paying very little attention to sponsors. It does not mean however, that all those who said this do not remember any of the sponsors, given that around two-thirds of the respondents recalled at least one sponsor, as was mentioned earlier in this section. Consequently, even if someone has a negative attitude towards the sponsors, it is still possible that they remember some of them. For sponsors aiming at brand awareness this might be an essential point. We do not know, however, to what extent JJK's sponsors behave consciously, if at all. According to a recent Finnish study (Itkonen et al. 2009), less than one-third of the companies tried to assess whether the terms of contract had been fulfilled or not.

JJK is advised to be careful with the number of sponsors. It is understandable that the club needs the income coming from sponsors and therefore they try to maximize the number of them, but results affirm that the numerous brands placed on players' kit and in the stadium are confusing for the spectators and, as demonstrated earlier, yields poor rate of recall. Furthermore, advertisements and encouragement to cheer for the team coming from loudspeakers was seen as lacking efficiency, and moreover, in the majority of the cases was considered disturbing. Therefore, it is recommended that these practices are discontinued. Altogether, less than one-fourth of the fans had positive attitude towards sponsors, such that they were interested in sponsors' products or try to use them in respect of various brands supplied. These results suggest that the sponsorship efficiency is limited for various reasons, such as a high number of sponsors causing confusion and fans being inattentive. It is believed that fans do not remember any brand 
names after their saturation point is exceeded. On the contrary, some results indicate that even the presence of brand names in the stadium might result in recognition by spectators.

When taking the sponsors' point of view of these circumstances presented, the following question emerges: Whether investing in a business with JJK is a conscious undertaking based on careful planning with the calculation of the return on investment for the sponsors, or is it more like a financial support to the most important football club of Central-Finland? The difference between donation (gift), traditional sponsorship (placing a logo on players' kit or in the stadium in return for money) and modern sponsorship (sponsor alignment) should be noted at this point. Market research based on former studies on sponsorship commitment (Chadwick \& Thwaites 2006; Farrelly \& Quester 2003) is highly recommended.

To conclude, a considerable option to improve the setting in which JJK's sponsorship business take place could be to restrict the number of sponsors and offering each of them a special and unique relationship with the team, including exclusive appearance in the stadium and players' kit, activities through which sponsor alignment can be achieved and partners could exploit the commercial potential of the association with JJK. For example, introducing a pre-match magazine with the opportunity for sponsors to present themselves in it, or organising social responsibility campaigns involving sponsors and players, through which contact with the fans are created, could be good examples. In return, JJK could expect more revenues from each of the sponsors and could maximize income without having countless sponsors.

\section{Fan identification/satisfaction and sponsor awareness}

This study has also found that fans on a higher identification level recall more sponsors. This result is presented in Table 1. Again, this outcome underpins the relevance of creating fan identification.

Table 1: Cross tabulation for fan identification and sponsor awareness

\begin{tabular}{|c|c|c|c|c|}
\hline $\begin{array}{c}\text { Degree of } \\
\text { being a JJK } \\
\text { fan }\end{array}$ & & $\begin{array}{c}\text { Recalling } \\
\text { sponsors } \\
\text { Did not } \\
\text { nameany } \\
\text { sponsors }\end{array}$ & $\begin{array}{l}\text { Recalled } \\
1 \\
\text { sponsor }\end{array}$ & $\begin{array}{l}\text { Recalled } \\
\text { more than } \\
1 \text { sponsor }\end{array}$ \\
\hline $\begin{array}{l}\text { Not } \\
\text { important }\end{array}$ & $\begin{array}{l}\text { Count } \\
\% \text { within Degree of } \\
\text { being a JJK fan (recoded) }\end{array}$ & $\begin{array}{r}22 \\
64,7\end{array}$ & $\begin{array}{c}1 \\
2,9\end{array}$ & $\begin{array}{c}11 \\
32,4\end{array}$ \\
\hline $\begin{array}{l}\text { Slightly } \\
\text { important }\end{array}$ & $\begin{array}{l}\text { Count } \\
\% \text { within Degree of being } \\
\text { a JJK fan (recoded) }\end{array}$ & $\begin{array}{c}10 \\
26,3\end{array}$ & $\begin{array}{c}6 \\
15,8\end{array}$ & $\begin{array}{r}22 \\
57,9\end{array}$ \\
\hline Important & $\begin{array}{l}\text { Count } \\
\text { within Degree of being a } \\
\text { JJK fan (recoded) }\end{array}$ & $\begin{array}{c}19 \\
29,7\end{array}$ & 4,7 & $\begin{array}{r}42 \\
65,6\end{array}$ \\
\hline $\begin{array}{l}\text { Very } \\
\text { important }\end{array}$ & $\begin{array}{l}\text { Count } \\
\% \text { within Degree of being } \\
\text { a JJK fan (recoded) }\end{array}$ & $\begin{array}{c}15 \\
28,8\end{array}$ & $\begin{array}{c}6 \\
11,5\end{array}$ & $\begin{array}{c}31 \\
59,6\end{array}$ \\
\hline
\end{tabular}

$(\mathrm{p}=.002)$
As expected, higher identified fans typically recall more sponsors ( $\mathrm{p}=.002)$. The most notable data here is that $28.8 \%$ of those who consider being a fan 'Very important' recall no sponsors whereas $59.6 \%$ recall more than 1 sponsor, and $64.7 \%$ of those who consider being a fan 'Not important' recall no sponsors while $32.4 \%$ recall more than 1 sponsors. On the other hand, although expected, fan satisfaction did not prove to influence the number of sponsors recalled.

This research has failed to justify an existing connection between sponsor orientation and fan satisfaction as well as fan identification, although past research has discovered (Shaw \& McDonald 2006) that although fans' reaction to sponsors' activities depends on various factors, there is an existing relationship between the levels of fan satisfaction and their attitudes towards sponsors. These results appear to be somewhat ambiguous concerning the influence of fan satisfaction/identification levels on sponsor awareness/ attitude. If a club presents a study confirming the positive relationships between the above-mentioned factors, sponsors could be attracted much easier.

Results were obtained by using cross tabulation analysis. Material on fan identification and fan satisfaction can be found in the complete master's thesis 'Marketing Analysis of JJK Jyväskylä, A First Division Football Club in Finland' of which this paper forms part of.

\section{Summary}

This paper has studied sport sponsorship in Finland through the case study of of a Finnish First Division football club, FC JJK Jyväskylä. The vast majority of the research has been conducted via the analysis of fans' opinion of JJK's operation. In addition, statistical data obtained from the club and found on the Internet, interviews accomplished with the leaders of JJK and the method of direct (participant) observation of numerous forms of interaction provided invaluable insight to JJK's marketing activities.

When coming to the research question on the sponsor awareness and sponsor orientation of JJK fans, this study has established an invaluable outcome. Only 13 out of the 200 sponsors that JJK had in 2008 were recalled by more than $5 \%$ of the respondents, and merely 3 sponsors' recallrate was considerable, i.e. more than $20 \%$. On the other hand, two-thirds of the respondents remembered at least one sponsor.

The investigation of the sponsor orientation has also presented poor results from the perspective of the sponsors. The majority of the people paid little attention to sponsors, and almost half of them were confused due to the high number of them. Additionally, announcement via loudspeakers were not recognized as efficient and very few fans had a positive attitude towards sponsors, such that they were trying to use their products or would receive more information on them. It can be concluded that owing to disinterested fans, the huge number of sponsors and the assumed lack of consciousness by the sponsors, efficiency stood at a low level. 
Getting to know this outcome may be helpful for JJK management when it comes to the improvement of marketing management. It is recommended to reconsider the system of sponsorship, in a way that concentrating on a restricted number of sponsors and offering them a unique relationship with JJK, can be more profitable for both the club and the sponsors. As a result, JJK could maximise the revenue coming from sponsors and in return, could offer sponsor alignment to its partners. To achieve this, however, firstly, sponsors need to be convinced about the benefits of behaving consciously, secondly, they should be involved in various activities to be able to get contact with JJK and its fans. An option to accomplish this goal by the club is to utilise the tools of relationship marketing and carry out regular market research that gives facts about the possible benefits/profits of being a sponsor.

The following major finding of this paper, which answers to the second research question, is that higher identified fans recalled more sponsors, which underscores the relevance of creating fan identification. This result is believed to contribute to the development of the management of sponsorship. On the contrary, there was no detected correlation between levels of fan satisfaction and recalling sponsors. Furthermore, in contrast to former studies (Shaw \& McDonald 2006), one unanticipated finding was that neither levels of fan satisfaction nor fan identification are related to the sponsor orientation of fans. At this point future investigation is advised.

\section{Limitations of this study and recommended further research}

Finally, a number of important limitations need to be considered. First, this work has been a case study, planned for particularly Finnish conditions, investigating only one football club. Therefore, it should be careful when generalising conclusions. Second, the source of the data analysed was an on-line questionnaire in English and that fact might have influenced the type of respondents. Third, although this study has found numerous relationships between various factors, these might be influenced with other factors that were not taken into account in this research. In addition, the nature of the relationships, i.e. direct or indirect, linear etc., as well as the direction of the relationship has been hard to comprehend.

Congruent research may be beneficial to conduct periodically for semi-professional and professional football clubs of periphery football countries, in order to enhance the level of marketing management and be able to fulfill the requirements of fans and sponsors. Furthermore, a more detailed research on each of the issue areas analyzed is believed to be worthwhile.

\section{References}

Atkinson, P. (2007): Handbook of Ethnography. Sage.

Bühler, A., Nufer, G. (2009): Relationship marketing in sports. London: Elsevier

Chadwick, S., Thwaites, D. (2006): Distinguishing between shortterm and long-term commitment in football shirt sponsorship programmes: towards a matrix of management implications, International Journal of Sports Marketing \& Sponsorship, 163-179 (May 2006)

Clark, S. (1992): Sponsorship in semi-professional football: a comparative study of Finland's Premier League and England's GM Vauxhall Conference League. University of Jyväskylä

Farrelly, F., Quester, P. G. (2003): What Drives Renewal of Sponsorship Principal/Agent Relationships? Journal of Advertising Research, 43 (4), 353-360

Hancock, B. (2002): Trent Focus Research and Development in Primary Health Care. An introduction to the Research Process. Trent RDSU, National Institute for Health Research.

Itkonen, H., Ilmanen, K., Matilainen, P. (2009): Sponsorship in the Finnish sport culture. European Journal for Sport and Society. 6 (1), 7-18

JJK Jyväskylä (2009): Jalkapalloa Jyväskylässä jo yli 80 vuotta. Retrieved November 9, 2009 from http://www.fcjjk.com/fi/ seura/?id=283

Lipponen, K. J. (1995): Strategic marketing of sport organisations to corporate sponsors: Development of a framework. University of Alaberta, Faculty of Business

Mathers, N., Fox, N., Hunn, A. (2006): Surveys and Questionnaires. Trent RDSU, National Institute for Health Research.

Research Methods Knowledge Base (2006). Introduction to Validity. Retrieved February 8, 2010 from http://www.socialresearchmethods. net/kb/introval.php

Pooley, J.C. (1978): The sport fan: A social psychology of misbehavior. Sociology of Sport, Monograph series. Canada: University of Calgary.

Shaw, R.N., McDonald, H. (2006): Season-ticket holder satisfaction and sponsor-related behaviour: evidence of a positive relationship. International Journal of Sports Marketing \& Sponsorship 7 (4), 318325.

Veikkausliiga (2008)__Retrieved May 14, 2008 from http://www. veikkausliiga.com/

Verhoeven, M., Laporte, W., De Knop, P., Bollaert, L., Taks, M., Vincke, J. (1999): In search of macro-, meso-, and micro sociology antecedents of conflict in voluntary sports federations and clubs with the Flemish situation as case study. European Journal For Sport Management, 6 (Special Issue), 62-77. 